\title{
Extensão universitária em saúde ginecológica de mulheres trabalhadoras: educação para promoção da saúde
}

\author{
University extension in gynecological health of working women: \\ education for health promotion \\ Extensión universitaria en salud ginecológica de mujeres trabajadoras: \\ educación para promoción de la salud \\ Fabiane Frigotto de Barros ${ }^{1}$, Adriana Cristina Franco ${ }^{2}$

\begin{abstract}
${ }^{1}$ Enfermeira Especialista em Pediatria e UTI Neonatal. Bolsista da CAPES. Mestranda em Ensino nas Ciências da Saúde pela Faculdades Pequeno Príncipe - FPP Curitiba Paraná

${ }^{2}$ Enfermeira Obstetra e do Trabalho, Mestre em Engenharia de Produção. Docente da Faculdades Pequeno Príncipe - FPP Curitiba-Paraná
\end{abstract}

\begin{abstract}
RESUMO
Objetivos: Desvelar a percepção de mulheres trabalhadoras sobre a Consulta de Enfermagem em Ginecologia no contexto da saúde ocupacional; Compreender os benefícios de um projeto de extensão universitária, voltado à saúde ginecológica de mulheres trabalhadoras, para a população atendida. Método: Estudo exploratório descritivo de abordagem qualitativa, a coleta das informações se deu por meio de entrevistas que foram gravadas e transcritas, e a análise de conteúdo se deu através da técnica proposta por Turato. Resultados e discussão: Os principais benefícios evidenciados foram vínculo profissional-cliente e educação em saúde, quanto à formação acadêmica, destaca-se uma aprendizagem ativa e significativa, através da autonomia que é desenvolvida pelo extensionista. Conclusões: A integração ensino, serviço e comunidade é apreendida como um grande benefício para a população atendida e a oferta deste tipo de atendimento faz-se necessária, para implementação de novas formas de educação em saúde e de abordagens que subsidiem o aumento da cobertura do Programa.
\end{abstract}

Palavras-chave: Educação em saúde. Saúde da mulher. Relações Comunidade-Instituição. Saúde Ocupacional. 


\begin{abstract}
Objectives: To unveil the perception of working women about the Nursing Consultation in Gynecology in the context of occupational health; to understand the benefits of a university extension project, focused on the gynecological health of working women, for the population served. Method: Exploratory descriptive study of a qualitative approach; the collection of information was done through interviews that were recorded and transcribed; content analysis was done through the technique proposed by Turato. Results and discussion: The main benefits evidenced were professional-client linkage, and health education; regarding academic training, an active and significant learning is highlighted, through the autonomy that is developed by the extensionist. Conclusions: The integration of education, service and community is perceived as a great benefit for the population served; the provision of this type of care is necessary, for the implementation of new forms of health education and approaches to subsidize the increase of the Program coverage.
\end{abstract}

Keywords: Health education. Women's health. Community-Institution Relations.

\title{
RESUMEN
}

Objetivos: Desvelar la percepción de mujeres trabajadoras sobre la Consulta de Enfermería en Ginecología en el contexto de la salud ocupacional; comprender los beneficios de un proyecto de extensión universitaria, orientado a la salud ginecológica de mujeres trabajadoras, para la población atendida. Método: Estudio exploratorio descriptivo del abordaje cualitativo, la recolección de las informaciones se dio por medio de entrevistas que fueron grabadas y transcritas, el análisis de contenido se dio a través de la técnica propuesta por Turato. Resultados y discusión: Las principales ventajas evidenciadas fueron vínculo profesional-cliente y educación en salud, en cuanto a la formación académica, se señala un aprendizaje activo y significativo, a través de la autonomía que es desarrollada por el extensionista. Conclusiones: La integración de la enseñanza, el servicio y la comunidad es percibida como un gran beneficio para la población atendida, la oferta de este tipo de atención se hace necesaria, para la implementación de nuevas formas de educación en salud y de enfoques que subsidien el aumento de la cobertura del programa.

Palabras clave: Educación en salud. Salud de la mujer. Relaciones entre la Comunidad y la Institución.

\section{INTRODUÇÃo}

O câncer de mama é a primeira causa de morte entre as mulheres, tendo seu padrão de morbimortalidade permanecido muito elevado no Brasil ${ }^{1}$.

O desenvolvimento do câncer de mama depende de diversos fatores como idade, história familiar de câncer de mama, história de câncer na mama contralateral, terapia de reposição hormonal por mais de 10 anos, menarca precoce e/ou menopausa tardia, nuliparidade e histórico de câncer de cólon ou de útero ${ }^{2}$.

Além destes fatores, as taxas crescentes deste câncer, em várias regiões do mundo, e o fato das mulheres ocuparem um papel diferente na sociedade atualmente, participando ativamente do mercado de trabalho, levam ao questionamento sobre a existência de fatores de risco ocupacionais para o câncer de mama ${ }^{3}$. 
O mesmo ocorre com o câncer de colo uterino, o qual está relacionado à infecção pelo HPV, como causa necessária de seu desenvolvimento, porém não constitui causa única. A infecção pelo papiloma vírus humano precisa estar aliada a outros fatores para o desenvolvimento de neoplasia, tais como a sexarca precoce, múltiplos parceiros sexuais, alimentação pobre em nutrientes, o tabagismo, a higiene íntima inadequada e o uso prolongado de contraceptivos orais, sendo a maioria das mulheres que vivenciam estas situações de classe socioeconômica baixa ${ }^{4-5}$.

A exemplo do que ocorre com o câncer de mama, vários destes fatores têm relação com o estilo de vida da mulher, que pode ser condicionado pelo seu trabalho, pois "a saúde é expressão de condições sociais, culturais e históricas das coletividades em que o trabalho desempenha papel crucial"6.

A característica da mulher na sociedade se transformou muito nas últimas décadas e atualmente temos um contexto onde a mulher passou a incorporar uma elevada proporção nas atividades ocupacionais, o que demonstra maior integração da mulher na sociedade e permite que ela ocupe seu espaço, mas em contrapartida muitas vezes está aliada a uma maior vulnerabilidade da trabalhadora frente à precarização do trabalho.

Aliado a isto, a rotina pesada e a conciliação entre trabalho, matrimônio, maternidade, feminilidade fazem com que os hábitos de vida da mulher nem sempre sejam tão saudáveis, sendo comum a diminuição de horas e qualidade do sono, má alimentação e déficit no autocuidado com a saúde.

As estratégias de rastreamento têm sido as grandes responsáveis pelo controle dos cânceres de colo e mama em países desenvolvidos, pois quando diagnosticados em fases iniciais têm grandes chances de cura. Mas no Brasil ambos são diagnosticados em fases muito avançadas diminuindo as possibilidades terapêuticas ${ }^{7}$.

Devido a todos estes fatores pode-se afirmar que há uma forte relação entre saúde e trabalho que condiciona o estilo de vida da mulher, que por si já gera diversos fatores de risco para doenças e, muitas vezes, dificulta o acesso aos serviços de saúde pela própria atividade laboral e o comprometimento que o trabalho demanda na rotina da trabalhadora.

Um agravante deste contexto é o fato de que os cânceres de colo uterino e mama não são considerados cânceres ocupacionais, o que leva as empresas a não focarem sua atenção à saúde das mulheres trabalhadoras em relação a tais doenças e muito menos investirem na prevenção delas. Entretanto, estudos mostram que interferências na saúde da mulher, mesmo que sejam menos graves, como, por exemplo, os distúrbios menstruais, além de ter relação com o trabalho, pela rotina estressante, fator emocional, impacto das condições de trabalho nos hábitos alimentares e padrão de sono, refletem na redução substancial da produtividade no local de trabalho e aumentam os índices de absenteísmo, gerando prejuízos para a empresa ${ }^{8}$.

Uma estratégia para incluir as trabalhadoras no rastreamento e diagnóstico precoce dos cânceres de colo uterino e mama é a oferta deste tipo de atendimento no próprio local de trabalho. Pensando nisso, um hospital pediátrico de grande porte de Curitiba oferta, desde 2006, um programa de prevenção destes cânceres, intitulado Mulher Saudável, cuja finalidade é realizar Consultas de Enfermagem em ginecologia, que percorrem as etapas de anamnese, exame físico, diagnóstico de enfermagem e prescrição, realizadas por estudantes extensionistas. A iniciativa surge aliando dois grandes eixos: a formação universitária e a qualidade de vida no trabalho, e desta forma o projeto busca desde então a integração ensino e serviço. Este projeto de Extensão recebe acadêmicos de todos os Cursos ofertados por uma faculdade da área de saúde vinculada à instituição hospitalar, através de uma perspectiva multiprofissional, transdisciplinar e interdisciplinar. 
Diante das questões supracitadas, este estudo justifica-se pela busca de compreensão de como este tipo de projeto de extensão pode trazer benefícios à comunidade e a percepção da população atendida sobre estes benefícios. Emergiu então, a seguinte questão norteadora: "Qual a percepção de mulheres trabalhadoras sobre a Consulta de Enfermagem em Ginecologia inserida num programa de extensão universitária em seu ambiente ocupacional?”.

\section{OBJETIVOS}

- Desvelar a percepção de mulheres trabalhadoras sobre a Consulta de Enfermagem em Ginecologia no contexto da saúde ocupacional;

- Compreender os benefícios de um projeto de extensão universitária, voltado à saúde ginecológica de mulheres trabalhadoras, para a população atendida.

\section{MÉTODO}

Estudo exploratório descritivo de abordagem qualitativa. As participantes do estudo foram 15 mulheres trabalhadoras de Instituição Hospitalar de grande porte de Curitiba, referência em pediatria. Os critérios de inclusão foram: Ser colaboradora legalmente registrada, com idade acima de 18 anos e que aceitou participar do estudo.

Para a coleta de informações foi utilizada uma entrevista semiestruturada contendo questões referentes ao perfil sociodemográfico, saúde ginecológica e percepção de mulheres trabalhadoras sobre o atendimento do projeto de extensão voltado à prevenção dos cânceres de colo uterino e mama no contexto ocupacional. Esta entrevista foi gravada e posteriormente transcrita.

Para garantir o anonimato das participantes foi atribuída a elas uma codificação, por nomes de flores, sendo identificada apenas a idade das participantes no resultado do estudo.

Para a análise das informações, foi utilizada a técnica proposta por Turato, que afirma poder-se entender o processo de tratamento de dados bem como a sua codificação, através de um processo no qual se transforma dados brutos até se atingir uma possível representação do conteúdo?.

1ํㅡㄹ - LEITURAS FLUTUANTES PARA IMPREGNAÇÃO DO DISCURSO: etapa de anàlise e organização do material obtido para se iniciar as leituras flutuantes, nesta fase foram realizadas leituras e releituras ao ponto de impregnar os discursos para se obter o que é mais significativo, ou seja, até o desvelamento da essência de seus conteúdos com clareza, para então iniciar a elaboração de dados, conceitos e teorias e subsidiar a construção das etapas seguintes?.

$2^{\mathbf{a}}$ etapa - CATEGORIZAÇÃO DE TÓPICOS EMERGENTES: nesta fase, Turato sugere que sejam elaboradas categorias e subcategorias. As categorias foram definidas por meio de um conjunto de discursos que remetem ao mesmo significado. A subcategorização consiste em pôr em destaque dentro de um grande tópico (categoria) outros tópicos particulares que merecem discussão em relevo, porém guardam certa dependência temática com amplo tópico categorizado?.

$3^{a}$ etapa - INFERÊNCIA E INTERPRETAÇÃO DOS RESULTADOS: esta etapa, construída após a categorização de tópicos emergentes, exige um processo lógico de derivar uma proposição da outra ou se obter uma conclusão a partir de determinadas premissas de acordo com certas regras operatórias. A posse dos resultados da pesquisa em mãos se faz acompanhar por automática interpretação, ocorrendo na consciência do pesquisador ainda que de 
modo pouco elaborado9.

O estudo atendeu aos pressupostos éticos contidos na resolução 466 de 12/12/2012, que dispõe sobre os aspectos éticos envolvidos nas pesquisas com seres humanos. Foi elaborado e oferecido o Termo de Consentimento Livre e Esclarecido (TCLE) para assinatura das participantes. A etapa de coleta de informações foi iniciada apenas após aprovação do Comitê de Ética sob o número de parecer 870.986 em $11 / 11 / 2014$.

\section{RESULTADOS}

Quanto ao perfil das participantes, prevaleceram mulheres solteiras, com idade entre 26 e 39 anos, com ensino superior incompleto. As categorias profissionais foram bastante diversas, sendo representadas por técnicas de enfermagem, estagiárias da área e enfermeiras, trabalhadoras de setores administrativos e dos serviços de apoio.

Nesta etapa, subsidiada pela flutuação dos discursos, emergiram grandes tópicos representados amplamente nos discursos, que foram agrupados e deram origem a uma categoria. Em seguida, dentro deste grande contexto observou-se a prevalência de outros grupos de discursos relevantes que foram agrupados, dando origem às subcategorias conforme elucidado na tabela 1.

A categoria Percepção da relevância da consulta de enfermagem em ginecologia à mulher trabalhadora em um projeto de extensão universitária apreende sob a ótica das participantes a importância do atendimento ginecológico com foco nas peculiaridades da mulher enquanto trabalhadora, e através da primeira subcategoria "Importância do vínculo profissional-cliente" verifica-se que para a continuidade e efetividade do acompanhamento da saúde da mulher a criação de um vínculo de confiança entre profissional e cliente faz-se essencial.
Tabela 1 - Tabela de categorias e subcategorias apreendidas

\begin{tabular}{l|l} 
Categoria & \multicolumn{1}{l}{ Subcategorias } \\
\hline $\begin{array}{l}\text { Percepção da } \\
\text { relevância da } \\
\text { consulta de } \\
\text { enfermagem em } \\
\text { ginecologia à mulher } \\
\text { trabalhadora em um } \\
\text { projeto de extensão } \\
\text { universitária; }\end{array}$ & $\begin{array}{l}\text { B. Educação em saúde } \\
\text { como instrumento do vínculo } \\
\text { de qualidade de } \\
\text { atendimentos } \\
\text { ginecológicos; } \\
\text { C. Os benefícios de se } \\
\text { cuidar no ambiente de } \\
\text { trabalho. }\end{array}$ \\
& Fonte: dados da pesquisa, 2015.
\end{tabular}

Ao analisar os discursos, pode-se desvelar que quando há um profissional de referência para a paciente e que transmite segurança a ela, os atendimentos geram maior satisfação e são mais resolutivos. Já quando ocorre o contrário, a mulher sente-se inibida a esclarecer suas dúvidas e não consegue ficar à vontade nas consultas, o que pode se refletir na diminuição da frequência da busca por prevenção, restringindo a procura ao atendimento ginecológico ao tratamento de queixas já instaladas.

"Ah eu achei ótimo, descobri faz pouco tempo, que uma funcionária também veio e contou, [...] pode ir que você vai adorar, porque ela é uma pessoa que te explica, tem que ver como ela explica bem você vai sair de lá satisfeita, falei ah então eu vou, porque uma que eu preciso e outra que para marcar no posto tem que ser só com o médico que tem lá, você não tem direito de escolher né, e eu acho que a gente tem que ter direito de escolher um profissional principalmente ginecologista pra você estar conversando, é muito intimo pra você estar falando, estar conversando, se não é um bom profissional você não fala nada, vai embora e acabou, então eu achei muito bom colocarem aqui principalmente para os funcionários, gostei muito" Cravo (46 anos).

Pode-se apreender ainda nesta subcategoria as implicações diretas que a falta de vínculo profissional- 
cliente pode ter sobre as consultas em saúde da mulher, sob o ponto de vista de quem as vivencia.

"A última vez que eu fui o médico quis me dar um anticoncepcional que eu não posso tomar, Diane sabe, por causa que, devido ao meu problema eu tenho que tomar um que não dê interferência com meu medicamento, a carbamazepina. Na última eu não saí satisfeita por causa disso de ele querer me dar um medicamento que eu não posso tomar, as demais foi normal" Orquídea (31 anos).

A falta de acompanhamento contínuo por um profissional mostrou-se relevante na percepção das participantes para experiências negativas nos atendimentos, pois a falta de vínculo não permite o conhecimento e compreensão do histórico da paciente e de seu estado de saúde em geral, envolvendo tanto seus aspectos físicos quanto emocionais.

\begin{abstract}
"Algumas sim, outras não né, porque na verdade eu tenho uma história, é... eu já tive dois abortos, nesse que eu tive antes de ter a minha filha, eu estava de 5 meses, então eu tenho tanto pontos positivos quanto negativos né, assim na parte ginecológica mesmo eu não tenho do que reclamar, o problema é que às vezes muda o convênio, o convênio muda e ai eu já não consigo marcar com o mesmo médico que eu já tinha afinidade, agora a parte obstétrica, a mesma coisa, tem os positivos e os negativos também” Tulipa (36 anos).
\end{abstract}

Tem-se ainda em sua visão que a criação de tabus e a não aderência a programas de prevenção podem estar relacionadas à falta de vínculo, que por sua vez pode estar associada aos valores, grau de instrução, cultura, religião e forma de educação, entre outros.

"[...] eu conheço pessoas que tiveram filho e, nossa, faz 5 anos que não vão ao ginecologista né, foram para tirar os pontos e nunca mais, então minha mãe foge de médico que é uma coisa, ginecologista jamais, porque é uma pessoa com uma educação diferente né, antiquada né, então ela não costuma ir no ginecologista né, e é uma coisa muito íntima né, e ela não consegue, é um bloqueio” Begônia (40 anos).
Ainda sobre a relevância do vínculo de confiança, também se verifica pelos discursos a valorização da consulta de enfermagem em ginecologia por parte das participantes, sendo esta entendida pela mulher trabalhadora como um atendimento com foco amplo e que propicia ambiente confortável tanto para a realização dos procedimentos como para a educação em saúde.

"[...] venho aqui com vocês né, para fazer o preventivo, acho muito importante, gosto né, me sinto confortável de vir com vocês, muitas pessoas dizem não vou lá porque eu tenho vergonha, eu digo não, com elas eu não consigo ter vergonha, sabe, eu sou mais, ao contrário com meu próprio ginecologista eu vou lá e ele ah vamos colher eu... não, vou lá com as meninas coletar, já sei que eu não preciso dele, que eu morro de vergonha mesmo, e eu fico tensa né, então é onde dificulta colher o material, então eu venho aqui que eu me sinto à vontade, me sinto melhor e me faz bem vir aqui” Lírio da Paz (39 anos).

Uma questão que emerge como destaque das consultas de enfermagem em saúde da mulher, sendo de acordo com o olhar das participantes extremamente significativo, é a forma diferenciada de abordagem para a realização do exame preventivo de Papanicolaou e exame clínico das mamas, pela ênfase em um acolhimento prévio que tranquiliza a mulher e cria um ambiente de maior conforto e segurança para a realização dos exames de prevenção.

"[...] no pouco tempo que eu fiquei aqui você me mostrou, você me explicou certinho, eu já fiquei mais... Eu falei não foi a primeira vez que eu fiz, mas eu cheguei aqui com medo, nervosa, você me explicou não, não fique nervosa, se você ficar nervosa é pior, eu não senti dor nenhuma, não senti desconforto, no momento que eu sentei aqui que a gente já começou a conversar eu já fiquei bem mais calma, mais aliviada, então achei tranquilo. [...]” Acácia (25 anos).

Dentro deste contexto surge a segunda subcategoria "Educação em saúde como instrumento de qualidade de atendimentos ginecológicos" que, para a mulher, evidencia que as orientações efetivas e a prática de educação 
em saúde durante as consultas de enfermagem as diferenciam de atendimentos realizados por outros profissionais, e são representados como um marcador de qualidade em sua percepção.

A falta de orientação sobre os procedimentos realizados deixa a mulher insegura para o atendimento ginecológico, estando relacionada aos tabus criados sobre a prevenção do câncer de colo uterino e ao medo do rastreamento, pelo desconhecimento da técnica e o desconforto de não saber o que está sendo feito com seu corpo durante a consulta.

"É foi, pra mim foi, eu acho que foi... Não teve assim... Só não vi o material que nem você me mostrou eu não vi, nunca tinha visto, só vi que ela pegou lá um negócio de inox lá, mas eu não vi que jeito que era, eu achava que era um negócio gigante, porque pra mim que ele era bem largo assim... porque dai enfia lá dentro, então ai eu não achava que era pequeno assim, então essa parte eu não fui bem, não fui explicada assim, não foi mostrado assim pra mim ver, é a primeira vez” Dália (37 anos).

"Ah orientação assim bem profunda não, [...] não tem explicação" Cravo (46 anos).

"Não. É bastante porque dai a gente acaba ficando com uma segurança maior no profissional que está fazendo né, porque quando o profissional simplesmente manda você deitar ali e abrir as pernas você não sabe o que ele está fazendo, você não tem noção do que ele pode estar fazendo com você, então quando você, antes de tudo, você é orientada, você sabe a situação do exame, porque você está passando por aquilo é bem mais fácil, é mais tranquilo, menos constrangedor, você fica menos tensa [...]" Lírio da Paz (39 anos).

Outro tipo de orientação de extrema relevância nos atendimentos ginecológicos, e que muitas vezes é negligenciado, é em relação à realização do autoexame das mamas em técnica adequada, principalmente sendo este um método de rastreamento acessível a toda a população, que necessita apenas de instrução para sua realização, ressaltando que, diferente do rastreamento para câncer de colo uterino, o rastreamento e o diagnóstico precoce do câncer de mama envolvem métodos menos acessíveis pelo alto custo e necessidade de encaminhamento por enquadramento da paciente em critérios clínicos.

Muitas participantes relataram a falta de orientação individualizada e por parte de um profissional de saúde anteriormente, sendo a elas mais comuns e acessíveis as informações divulgadas na mídia sobre o câncer de mama.

“Também não, no caso só o que a gente vê na TV né, até eu nem imaginava fazer pelo fato da idade que eu sei que geralmente até a mamografia você faz com uns 40, 35 por ai, e profissional não, só pela TV” Acácia (25 anos).

Mesmo para aquelas que buscam informações sobre o autoexame e se preocupam com a realização da técnica, há experiências negativas de falta de orientação adequada.

\footnotetext{
"Não, o pior que não, nunca, nunca fui, tanto é que eu fui uma vez no postinho e eu queria fazer né, mas dai ela falou ah não você é muito nova, você não precisa, mas dai nem me orientou, falou como... que eu tinha medo também né, eu tenho muito medo, conheço mulher assim né, então eu falei ai eu tenho medo né queria fazer um exame pra ver, mas...” Margarida (37 anos).
}

Verifica-se ainda, que mesmo aquelas participantes que relatam orientação profissional prévia percebem na consulta de enfermagem um diferencial relacionado a informações mais completas e esclarecimento de dúvidas.

"já tinha sido orientada pela própria ginecologista, mas não tanto quanto você orientou da parte da axila, do osso do meio aqui né, foi bem mais completo o de hoje [...]" Copo de leite (32 anos).

"Na verdade na faculdade eu tive, teve uma pincelada sobre isso né, mas elas falaram daquele dedinho assim... Então, não foi nada muito profundo, orientação mesmo assim não, só tive agora" Papoula (18 anos).

Paras aquelas que já criaram vínculo com o local de 
estudo e possuem um histórico e maior frequência de atendimentos, a educação em saúde faz-se presente e foi considerada um indicador de qualidade significativo para a aderência e continuidade dos cuidados.

"Já, aqui também né, em 2013 quando eu fiz o preventivo em 2013 vocês me explicaram bem, no projeto. Antes orientada assim particularmente não, a gente tem as orientações assim, às vezes de televisão né, porque eu acho que é bem divulgado e quem não faz não tem como dizer não fui informada.” Dama da noite (30 anos).

"[... eu me senti segura e acho muito gratificante a gente ter a oportunidade de conhecer melhor o corpo da gente, de saber diagnosticar um câncer de seio, saber que eu acabei conhecendo melhor o meu corpo através de orientação dada pela equipe do projeto, foi muito importante pra mim [...] pra mim foi muito importante, talvez até por isso que eu voltei aqui tantas outras vezes”. Lírio da Paz (39 anos).

Sendo a educação em saúde na percepção das mulheres trabalhadoras um grande diferencial da consulta de enfermagem ofertada a elas, apreendese diversos discursos que ressaltam as principais orientações recebidas na consulta realizada no projeto e o aprendizado que isto as proporcionou sob seu ponto de vista.

"O exame e o... o dos dois o da mama e o do colo, eu não sabia que podia dar aqui, sabia que podia dar na mama, mas não em vários lugares" Orquídea (31 anos).

"Como ver do câncer de mama, como palpar, como me comportar numa consulta porque eu não fazia ideia de como que era, o colo do útero, que eu achei muito interessante, porque eu não tive saúde da mulher e como é importante eu fazer o exame né, pra eu fazer o autoexame, e acho que é isso" Papoula (18 anos).

Além do aprendizado sobre os cânceres de colo uterino e mama, na percepção das participantes, o trabalho de conscientização sobre a importância da prevenção destas neoplasias e o acolhimento realizado foram de extrema relevância durante a consulta de enfermagem.
"O autoexame, que eu não preciso ficar nervosa porque é uma coisa que é para meu próprio bem [...] bem melhor a prevenção do que remediar” Acácia (25 anos).

"Tomar vergonha na cara e não deixar de fazer o preventivo! Que é uma coisa importante né, mas às vezes que nem você fala, mil vezes fazer o exame e se tiver a doença pegar no começo do que... que nem eu ficava, ai eu tenho que trabalhar, ai eu não tenho tempo, aí vem o resultado você está com câncer... Aí você vai ter tempo? Por que não arranjar tempo antes da doença? Então isso que eu aprendi, ainda mais né as minhas filhas, a mais velha que já tem 25 anos fica no meu pé, isso é muito importante, muito importante os filhos ficarem no ouvido da mãe" Girassol (41 anos).

Além disso, a orientação da técnica correta para realização do autoexame das mamas também foi muito significativa, pois esta era desconhecida por grande parte das participantes.

"A questão dos dedos né, que até então, a gente vê sempre né, nas palestras que eu já vi até hoje foi sempre um dedo de cada vez na mama, eu acho que foi isso que eu não sabia mesmo, foi novidade, foi isso, a questão de como fazer o autoexame” Dama da noite (30 anos).

É ressaltada ainda nos discursos a importância destas orientações, pois muitas participantes relataram nunca terem sido orientadas anteriormente quanto ao autoexame.

"Ah, esse negócio de apalpar as mamas né que os outros não falavam né, eles faziam e ficavam quietinhos, porque geralmente os enfermeiros do posto chegam, faz e não fala nada, fica tudo só com elas [...]" Onze horas (49 anos).

As orientações sobre a técnica de coleta do preventivo de Papanicolaou também foram citadas como aprendizado e na percepção das participantes fizeram grande diferença em relação à diminuição do desconforto e insegurança para sua realização.

"É ali a parte que eu achava que você via tudo ali dentro do útero, isso foi novidade pra mim [...] eu achava que era um negócio gigante que abria e você via tudo, então isso 
foi novidade” Dália (37 anos).

"[...] e aprendi também o porque e como era feita a coleta do preventivo, que era uma das situações que eu não conhecia né, então isso me fez bem [...]"Lírio da Paz (39 anos).

A terceira subcategoria "Os benefícios de se cuidar no ambiente de trabalho" demonstra a importância da implementação da consulta de enfermagem em saúde da mulher com foco ocupacional, levando em consideração as particularidades das trabalhadoras, como rotina determinada pela carga horária e atividade laboral desenvolvida, que se reflete em padrões de sono, descanso, alimentação, prática de exercícios físicos ou sedentarismo, autocuidado e dificuldade de acesso aos serviços de saúde, muitas vezes atribuído à rotina pesada, o que pode interferir diretamente no surgimento de afecções ginecológicas, que quando não tratadas e persistentes podem ter influência sobre o desenvolvimento de câncer cervical.

Desta forma, justifica-se a relevância do cuidado prestado no local de trabalho, que entre outros benefícios, na percepção das participantes, leva a uma maior comodidade e facilidade de acesso, o que permite uma maior frequência de procura por atendimento.

"Eu acho ótimo, a praticidade que eu tive de não precisar sair do meu trabalho né [...]” Begônia (40 anos).

"Olha, como trabalhadora é como eu falei, facilita bastante a minha vida, porque as vezes como eu sei que é importante fazer o preventivo, anualmente, as vezes eu marco consulta só para isso e as vezes nem é com aquele médico da minha preferência né, que já mudou o médico, e aqui eu sei que tem a facilidade de eu estar no meu ambiente de trabalho, eu sei que é seguro, eu sei que o resultado é rápido, então porque não né, então eu acho que se puder continuar, pra mim vai ser... eu gosto muito!" Tulipa (36 anos).

É enfatizado por elas que se não tivessem sido atendidas no local de trabalho enfrentariam dificuldades no acesso à prevenção, e por este motivo possivelmente não realizariam o exame, como já ocorreu em experiências anteriores.

\footnotetext{
"Nossa, eu acho ótimo, ótimo mesmo porque é muito complicado ir na saúde pública, ainda mais a gente assim que estuda e trabalha, e geralmente é para tarde que eles marcam né, só que a tarde eu não posso” Papoula (18 anos).
}

Apreende-se nos discursos a preocupação que as mulheres trabalhadoras têm em relação ao absenteísmo para o cuidado com a saúde ginecológica e o fato de não precisar se afastar do trabalho para realizar a prevenção dos cânceres de colo uterino e mama e de outras afecções, a saúde da mulher é muito valorizada por elas, sendo destacado como um dos maiores benefícios de serem atendidas no Projeto de Extensão de Mulher Saudável.

"Você não perde tempo, não perde dia de serviço, porque é uma dificuldade no posto, você vai lá, perde tempo, pega uma declaração [...] aqui eles não aceitam uma declaração com carimbo de enfermagem e assinatura de enfermagem, você só perde hora, então por isso que é bom [...] facilita" Onze horas (49 anos).

Além da diminuição das taxas de absenteísmo e facilidade de acesso, sob a ótica das participantes, outro grande benefício de realizar as consultas de enfermagem no local de trabalho é o fato de este ser um local que tem seu atendimento voltado à educação em saúde, por sua própria característica de integração entre ensino e serviço, sendo as orientações um grande atrativo para estas mulheres.

"Ah é muito bom, foi bom, foi rápido né, e também assim eu acho que das outras vezes que eu fiz eu não tive assim essa palestra que você está dando aqui pra mim agora né, e de também assim, eu acho importante sabe o que... que parece que se aproxima mais conversar e a gente relaxa mais né, não chega aqui ah nós vamos ali fazer, acho que vai dar mais vergonha né e vai ser mais chato, assim foi ótimo!” Dália (37 anos). 
"Acho que facilitou muito, não só por estar no trabalho né, mas por conta das orientações, que passaram, eu achei bem válido, muito válido, e gostei bastante, gostei muito" Rosa (22 anos).

Para as participantes, a própria oferta deste tipo de atendimento pela Instituição empregadora demonstra uma preocupação com a saúde dos colaboradores e constitui forma de incentivo ao funcionário para o desenvolvimento de um trabalho cada vez melhor.

\footnotetext{
"Maravilhoso, eu sempre falo pra eles continuem, isso incentiva o funcionário, saber que você é acolhido neste momento, [...] incentiva o funcionário, me sinto acolhida por eles, eu me sinto assim que eles se preocupam se eu estou bem de saúde e eles me dando isso com certeza o meu rendimento no trabalho vai ser bem melhor" Girassol (41 anos).

"Ah, eu acho muito importante, é tudo de bom, eu acho que deveria existir mais outros projetos, [...] o trabalho de vocês é muito importante" Lírio da Paz (39 anos).
}

\section{DISCUSSÃo}

Emergiram nos discursos como grandes benefícios do atendimento no projeto de extensão o olhar holístico dos estudantes que participam dos atendimentos, com uma anamnese completa e preocupada com a saúde integral da mulher, e com a existência de fatores de risco ocupacionais e a extensa educação em saúde, com orientações sobre os procedimentos a serem realizados, sendo ressaltadas as orientações sobre o autoexame das mamas, as formas de prevenção dos cânceres e seus fatores de risco.

O Exame Clínico das Mamas complementa a política de alerta à saúde das mamas como método de diagnóstico precoce, sendo o procedimento realizado para avaliar sinais e sintomas referidos por pacientes na investigação diagnóstica, com o intuito de reconhecer e diferenciar alterações suspeitas de câncer daquelas relacionadas a condições benignas. Também destaca-se como uma oportunidade para o profissional de saúde informar a população feminina sobre o câncer de mama, os sinais de alerta, fatores de risco, detecção precoce, fortalecendo as ações de educação em saúde ${ }^{10}$.

O ensino e o incentivo das técnicas do exame clínico das mamas são de grande relevância, enfatizando que este é um procedimento tão eficaz e de custo extremamente reduzido, e que a realização da palpação das mamas serve também como um grande motivador para a mulher aderir aos programas de prevenção por permitir o reconhecimento de que o câncer de mama é um perigo em potencial ${ }^{11}$.

Percebeu-se que na percepção das participantes é relevante o vínculo de confiança entre cliente e profissional, ao realizar um acolhimento diferenciado a esta mulher, pautado no respeito à autonomia, no conhecimento do próprio corpo, em orientações completas e esclarecimento de dúvidas e, consequentemente, na quebra de medos, tabus e receio em realizar a prevenção.

\section{CONCLUSÕES}

Concluiu-se que a integração entre ensino, serviço e comunidade é apreendida como um grande benefício para a população atendida.

Quanto à percepção das trabalhadoras sobre a Consulta de Enfermagem em Ginecologia inserida em um programa de extensão universitária em seu ambiente ocupacional, conclui-se que para elas este é um atendimento baseado na criação de um vínculo de confiança entre profissional-cliente, importante para a continuidade dos cuidados e aderência às orientações.

A educação em saúde realizada pelos extensionistas mostrou-se um grande diferencial percebido por elas em relação a outros tipos de atendimento em saúde da mulher, que traz uma maior segurança e satisfação devido ao acolhimento realizado e às orientações individualizadas, pautadas nas peculiaridades da mulher enquanto trabalhadora e mais completas 
segundo o ponto de vista das participantes.

Tem-se ainda que o conhecimento da percepção das trabalhadoras sobre a importância da oferta deste tipo de atendimento dentro da Instituição faz-se necessário, para a implementação de novas formas de educação em saúde e de abordagens que subsidiem o aumento da cobertura do Programa.

Já quanto aos benefícios para formação acadêmica, este tipo de programa permite uma aprendizagem ativa e significativa ao estudante, através da autonomia que é desenvolvida no extensionista, o qual tem o papel de realizar as consultas de enfermagem em saúde da mulher, sob supervisão do enfermeiro responsável pelo serviço, aliando teoria à prática, desenvolvendo competências e preparando-se para suas atividades do futuro cotidiano profissional.

\section{REFERÊNCIAS}

1. Zapponi ALB, Tocantins FR, Vargens OM da C. A detecção precoce do câncer de mama no contexto brasileiro. Rev Enferm. 2012;20(3):386-90.

2. Bader TJ. Segredos em Ginecologia e Obstetrícia. 3. ed. Porto Alegre: Artmed, 2007. p.152.

3. Goldberg MS, Labrèche F. Occupational risk factors for female breast cancer: a review. Occup Environ Med [Internet]. 1996;53(3):145-56. Available from: http://www.ncbi.nlm.nih. gov/pubmed/8704854

4. Rama CH, Roteli-Martins CM, Derchain SFM, LongattoFilho A, Gontijo RC, Sarian LOZ, et al. Prevalence of genital HPV infection among women screened for cervical cancer [Prevalência do HPV em mulheres rastreadas para o câncer cervical]. Rev Saúde Pública [Internet]. 2008;42(1):123-30. Available from: http://www.scopus.com/inward/record. url?eid=2-s2.0-38849110073\&partnerID=40\&md5=f74f3a1f047 2b409e78b67adb37e10d6

5. Brasil. Ministério da Saúde. Instituto Nacional de Câncer. SISMAMA - Informação para o avanço das ações de controle do câncer de mama no Brasil. 2010;1-8. Available from: http:// www1.inca.gov.br/inca/Arquivos/Sismama.pdf
6. Brito, JC de. Enfoque de gênero e relação saúde/trabalho no contexto de reestruturação produtiva e precarização do trabalho. Cad Saúde Pública [Internet]. 2000 Jan [cited 2018 Sep 10] ; 16( 1 ): 195-204. Available from: http:// www.scielo.br/scielo.php?script=sci_arttext\&pid=S0102311X2000000100020\&lng=en. http://dx.doi.org/10.1590/S0102$311 \mathrm{X} 2000000100020$

7. Santos RS, Melo ECP, Santos KM. Análise espacial dos indicadores pactuados para o rastreamento do câncer do colo do útero no Brasil. Texto e Contexto - Enferm. [Internet]. 2012 Dec [cited 2018 Sep 10] ; 21( 4 ): 800-810. Available from: http://www.scielo.br/scielo.php?script=sci_arttext\&pid=S010407072012000400010\&lng=en. http://dx.doi.org/10.1590/S010407072012000400010

8. Smith DR. Menstrual disorders and their adverse symptoms at work: An emerging occupational health issue in the nursing profession. Nurs Heal Sci. 2008;10(3):222-8.

9. Turato ER. Tratado da metodologia da pesquisa clínicoqualitativa: construção teórico-epistemológica, discussão comparada e aplicação nas áreas da saúde e humanas. 3 ed. Petropólis, RJ: Vozes, 2008.

10. Ministério da Saúde. Controle dos cânceres do colo do útero e da mama. Cadernos de Atenção Básica n. 13; Série A. Normas e Manuais Técnicos. 2006. 124 p.

11. Gonçalves LLC, Lima AV, Brito ES, Oliveira MM de, Oliveira LAR de, Abud ACF, et al. Mulheres portadoras de câncer de mama. Rev Enferm UERJ, Rio Janeiro. 2009;17(3):362362-7. 